\title{
[k], [g] and [?] in Amman: Social associations and identity perception in young rural [fallahin] Palestinian speech
}

\author{
Shahd Abu Nahel \\ West Virginia University, sia0008@mix.wvu.edu
}

Follow this and additional works at: https://researchrepository.wvu.edu/etd

Part of the Arabic Language and Literature Commons, and the Other Languages, Societies, and Cultures Commons

\section{Recommended Citation}

Abu Nahel, Shahd, "[k], [g] and [?] in Amman: Social associations and identity perception in young rural [fallahin] Palestinian speech" (2021). Graduate Theses, Dissertations, and Problem Reports. 8114. https://researchrepository.wvu.edu/etd/8114

This Thesis is protected by copyright and/or related rights. It has been brought to you by the The Research Repository @ WVU with permission from the rights-holder(s). You are free to use this Thesis in any way that is permitted by the copyright and related rights legislation that applies to your use. For other uses you must obtain permission from the rights-holder(s) directly, unless additional rights are indicated by a Creative Commons license in the record and/ or on the work itself. This Thesis has been accepted for inclusion in WVU Graduate Theses, Dissertations, and Problem Reports collection by an authorized administrator of The Research Repository @ WVU. For more information, please contact researchrepository@mail.wvu.edu. 


\section{[k], [g] and [?] in Amman: Social associations and identity perception in young rural [fallahin] Palestinian speech}

Shahd Abu Nahel 
[k], [g] and [?] in Amman: Social associations and identity perception in young rural [fallahin] Palestinian speech

\author{
Shahd Abu Nahel \\ Thesis submitted to the Eberly College of Arts and Sciences \\ At West Virginia University \\ for the degree of Master of Arts in Linguistic
}

\author{
Sergio Robles Puente, Ph.D., Chair \\ Jonah Katz, Ph.D., \\ Nicole Tracy Ventura, Ph.D., \\ Department of World languages, literatures, and linguistics
}

\title{
Morgantown, West Virginia
}

2021

Keywords: dialects, Amman, language change, Amman's dialect, gender, social variables.

Copyright: Shahd Abu Nahel 


\begin{abstract}
[k], [g] and [?] in Amman: Social associations and identity perception in young rural [fallahin] Palestinian speech

Shahd Abu Nahel
\end{abstract}

Built after several immigration waves, Amman developed its own dialect. Previous studies investigated the stylistic and social reallocation process (Britain \& Trudgill, 2005) that happened to some major phonemes. The three phonemes [k], [?] and [g] are dialectal reflexes of the Arabic modern standard uvular phoneme [q], and they correlate with social aspects like gender, identity and social class. This study has two parts the first investigates the distribution of the phonemes of the first generation of rural Palestinians hypothesizing that they will follow the generalizations found in Al-Wer (2011). The second part is a large-scale questionnaire targeting the social assumptions of the use of the three reflexes, taking gender and social class into account. The results suggest that three reflexes are being strongly associated with social class rather than gender. 


\section{Table of Contents}

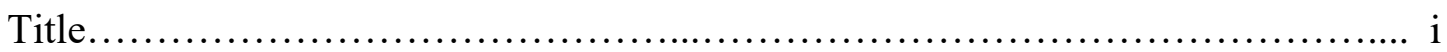

Abstract.................................................................... ii

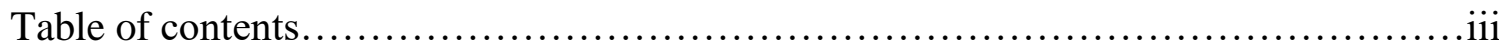

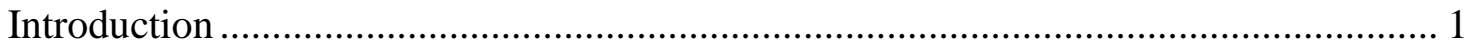

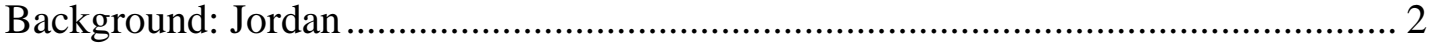

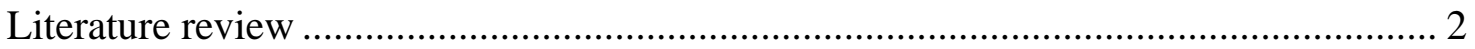

Jordan's dialects: Classifications ....................................................................... 3

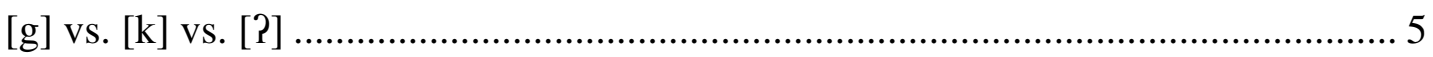

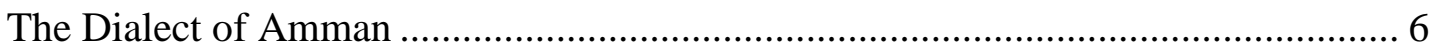

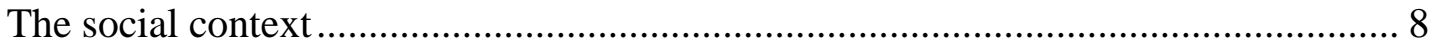

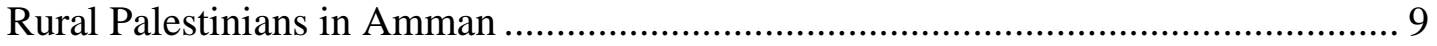

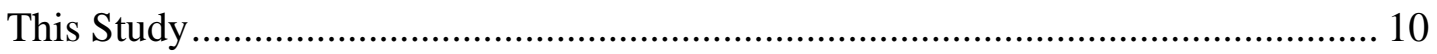

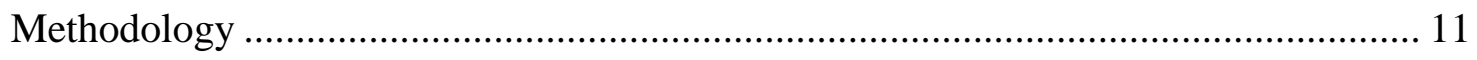

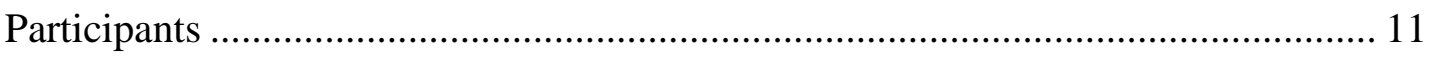

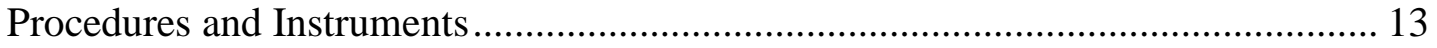

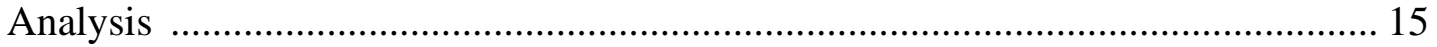

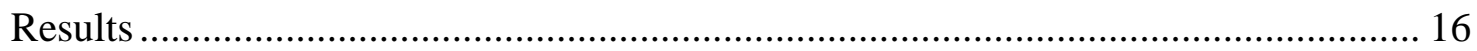

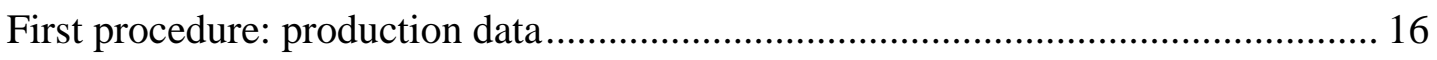

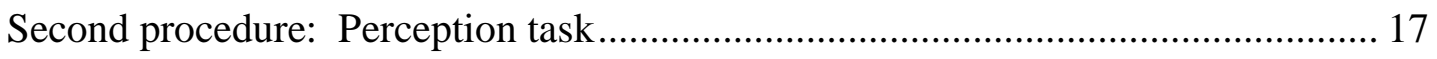

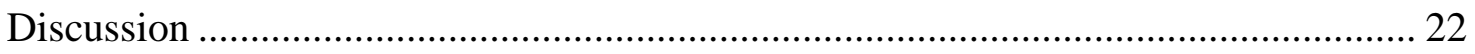

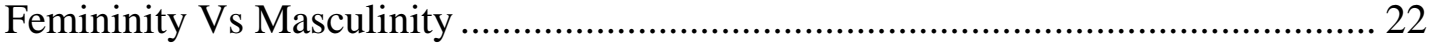

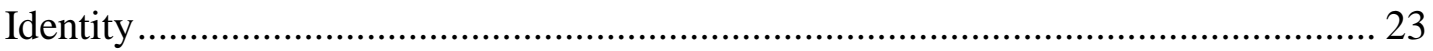

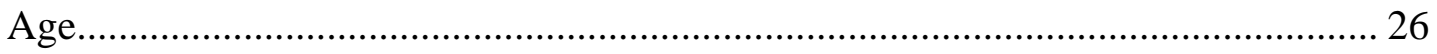



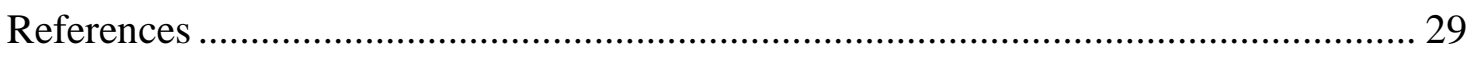

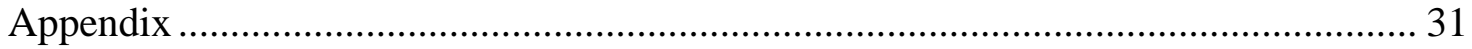



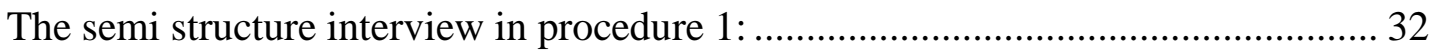

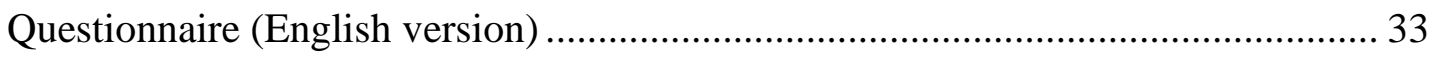




\section{Introduction}

The Arabic language is often described as a diglossic language (Abd-El-Jawad, 1986). This language duality means that the Standard form is used mainly for books, schools, and political speeches while Arabs speak a local dialect in their daily life. Arabic dialects make many changes in different levels of Standard Arabic, and those dialects contact, merge, and create new dialects over time.

Many sociolinguists have documented dialects in contact after the publication of Trudgill book (Smith \& Trudgill, 1987). Documented situations included the contact between different English dialects (Williams \& Kerswill, 1991), and the relationship between dialect change and industrialization and immigrations (Kerswill, 2018) (Trudgill, Britain, \& Cheshire, 2003).

Amman, the capital of Jordan, is one of those documented cases where two dialects merged and formed a new dialect. However, capturing the changes and developments of original, fusion and new features of the new dialect can be challenging. For example, Researchers may find it difficult to distinguish whether a feature is contact-induced or a linguistic development of the input dialect (Al-Wer, 2007). Amman's dialect, however, is different since it is formed from scratch. Having no stable population, Amman did not have a dialect to be influenced or developed (Al-Wer, 2007). It was formed through immigrants' dialects from two cities having two distinguished dialects; Nablus with urban Palestinian dialect, and As-Salti with Jordanian dialect. Jordanian dialects are Bedouin and they are two types: the dialects of nomad Bedouins and dialects of sedentary ones. As-salts' dialect is considered sedentary Bedouin (Al-Wer, 2007). Previous research samples (Al-Wer, 
2007, 2011) focused on the Nablus and As-Salti populations in Amman, excluding rural Palestinians who use $[\mathrm{k}]$.

Background: Jordan

\section{Literature review}

Jordan is a small country in the Middle East, historically known as "Trans-Jordan" or the east bank of the Jordan River and has been inhabited for millions of years (Al-Nhar, 2013). Roman, Persian, Egyptian, and lastly, Islamic civilizations ruled over Jordan, and influenced its culture and history. Between the sixteenth and the nineteenth centuries, Jordan was under the Ottoman reign, and it was neglected during this period. Many unjust reformations and decisions eventually led to the Great Arab Revolt in 1916 (Bakhit, Pascual, \& Mundy, 2013; Neveu, 2013). Afterwards, Jordan was under the British mandate. In 1912, the Hashemites ${ }^{1}$ created "Imarat Sharq Al-Urdun" - The Emirate of Trans-Jordan (Méouchy, Neveu, \& Ababsa, 2013). Then in 1946, Jordan became an independent state under the name "The Hashemite Kingdom of Jordan". Now, it is a modern state with a population of 10 million according to the department of statistics $2019 .^{2}$

\footnotetext{
${ }^{1}$ The Hashemites (Arabic: الهانثميون, Al-Hāshimīyūn; also House of Hashim) are the royal family of Jordan, which they have ruled since the implementation of the Sharifian Solution in 1920-21, and which also granted the family the thrones of the Syria (1920), Hejaz (1916-1925) and Iraq (1921-1958). The current dynasty was founded by Sharif Hussein ibn Ali, who was appointed as Sharif and Emir of Mecca by Sultan Abdul Hamid II in 1908, then in 1916 was proclaimed King of Arab countries (but only recognized as King of the Hejaz) after initiating the Arab Revolt against the Ottoman Empire. His sons Abdullah and Faisal assumed the thrones of Jordan and Iraq in 1921.

${ }^{2}$ http://dosweb.dos.gov.jo/
} 
Throughout the years, Jordan witnessed many immigration waves from Arab countries. The most influential one was from Palestinians in 1948 due to the Palestinian Israeli conflict. Approximately 70,000 Palestinians sought refuge in Jordan in 1948, and by the 1950s, the Palestinian population reached 400,000. The Unification of the two Banks ${ }^{3}$ influenced the demographic situation of Jordan. Nearly half a million Palestinians automatically became Jordanian citizens (Al Husseini, 2013). From 1990-1991, about 300,000-400,000 Palestinians fled from Kuwait to Jordan due to the Gulf Crisis (Van Hear, 1995). Therefore, those dramatic changes led to other linguistic ones.

Taking into account the social context of Amman, many constructs will be involved in investigating the most marked feature [q] reflexes. Where glottalizing [q] is a typical feature of urban Palestinians, velarizing it to $[\mathrm{g}]$ is a typical Jordanian dialect feature. The last reflex, which will be the core of this study, is [k], a typical rural Palestinian dialect sound. This study will investigate the social patterns in young rural Palestinians' speech using three sounds [k, g, ?].

Jordan's dialects: Classifications

Although it has a distinguished history, population, and culture, Jordan was considered as a part of "Greater Syria" or "Bilad Ash-sham", which consists of Jordan,

\footnotetext{
${ }^{3}$ On April 11, 1950, elections were held for a new Jordanian parliament in which the Palestinian Arabs of the West Bank were equally represented. Thirteen days later, Parliament unanimously approved a motion to unite the two banks of the Jordan River, constitutionally expanding the Hashemite Kingdom of Jordan to safeguard what was left of the Arab territory of Palestine from further Zionist expansion. The Hashemite Kingdom of Jordan now included nearly one and a half million people, more than half a million of whom were refugees evicted from Jewish-occupied Palestine. All automatically became citizens of Jordan, a right that had first been offered in December 1949 to all Palestinians who wished to claim it.
} 
Syria, Lebanon, and Palestine. In the 1900s, scholars started to draw classifications for the sedentary dialects in the region. In 1915, Bergsträsser published his classification "Sprachatlas von Syrien und Palästina" which covered the dialects from Aleppo to Petra in the south of Jordan. This classification was built on limited fieldwork, although it is considered the start point for later classifications (Palva, 2015). In 1938, Cantineau published his short paper "Remarques sur les parlés de sédentaires syro-libanopalestiniens", which focuses on the northern borders of the sedentary Palestinian dialects (Cantineau, 1938).

Cleveland's paper was the first classification of the Jordanian dialects in 1963. In his distinguished paper, "A Classification for the Arabic Dialects in Jordan", Cleveland presented four groups corresponding to the lifestyle and the reflex of the phoneme [q] and the imperfect morpheme [b-]. He used the Arabic verb [yaqu:1] "He said". Notably, the four groups have different lifestyles. The first group [yigu:1], are the Bedouins in the eastern and southern desert of Jordan. The second group is [bəgu:1], and they are rural southern Palestinians, Jordanians, and nomads settled in the Jordan valley and the east bank. The third group is [bəku:l], and they are the rural Palestinians [fellahin] in central Palestine. The last group is [bəPu:1], and they are the Palestinians in urban centers like Jerusalem and Haifa (Cleveland, 1963).

About 20 years later, Palva (1984) drew the second modified classification according to phonological and morphological criterions. His paper questioned the previous classifications. It provided more evidence supporting dialects' characteristics in Cleveland's classification. Moreover, it added the rest of the Palestinian dialects, the settled, as well as the Bedouin Jordanian dialects to the map. 
Questioning the old classifications did not stop with Palva. It was widely believed that the sedentary Jordanian dialect was originated from the Palestinian dialect (Herin, 2013). The recent research findings show that the sedentary Jordanian dialect, presented with As-Salti dialect, originated from the Horani dialect of northern Jordan (Herin, 2013). One of the strongest evidences is $[\mathrm{q}]$ and $[\mathrm{k}]$ realization. The Jordanian dialect maps $[\mathrm{q}]$ to [g] e.g. [qmi:s]- [gami:s] (shirt) while the Palestinian rural dialect maps it to [k] e.g.

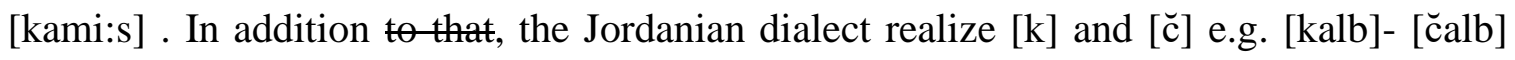
( $\operatorname{dog}$ ) as separate phonemes while the Palestinian dialect maps $[\mathrm{k}]$ to [ $\breve{\mathrm{c}}]$ unconditionally.

[g] vs. [k] vs. [?]

Arabic inventory consists of thirty-four sounds: twenty-eight consonants and six short and long vowels (Alfozan, 1989) See Appendix. It is worth mentioning that the phenomena of [q] reflexes is not allophonic nor neutralized since it does not result in any contrast. Table 1 below summarizes the contrastive consonants in modern standard Arabic, and the dialects in Amman.

\begin{tabular}{|l|l|l|}
\hline MSA & $\begin{array}{l}\text { Nabulsi Dialect } \\
\text { (Palestinian) }\end{array}$ & $\begin{array}{l}\text { As-Salti Dialect } \\
\text { (Jordanian dialect) }\end{array}$ \\
\hline$[\mathrm{k}][?]$ & $\begin{array}{l}{[\mathrm{k}][?]} \\
{[\mathrm{q}=\mathrm{P}]}\end{array}$ & $\begin{array}{l}{[\mathrm{k}][?]} \\
{[\mathrm{q}=\mathrm{g}]}\end{array}$ \\
\hline
\end{tabular}

Table 1: the consonants of MSA, Nabulsi and As-Salti dialects

The uvular stop [q] is one of the most important variables in studying Arabic dialects. The [q] reflexes are usually used to label dialects such as [gilit] dialects which refer to 
Mesopotamian dialects (Al-Wer \& Herin, 2011). The uvular stop [q] also functions as a variable in Jordan. It was used, as discussed previously, to label the dialects in TransJordan. Although [q] has different variants: $[\mathrm{g}],[\mathrm{k}],[\mathrm{q}]$ and [?], not all of them function as a variable in Jordan's case.

Following approaches and techniques developed by Labov and his associates, AbdelJawad (1986) collected hundreds of tapes and recordings. Recordings included: individuals, families, friends, markets, prayers, and classrooms. The sample had material representative of most groups in Amman's population. His study states that [g] and [?] has spread in the Jordanian urban centers due to Palestinian immigrants and participants, irrespectively of their dialectal background, [?] to refer to the same items e.g. [su:g] [su:?] (market). Besides, [k] was investigated in terms of standardization change on the affricated [c] in the Jordanian dialects. That led to the conclusion that the dialects in Jordan, especially in Amman, underwent a dramatic change (Abd-El-Jawad, 1986).

\section{The Dialect of Amman}

Due to the political situations in the region starting from 1940s, Jordan's population increased significantly. Amman's population started with 5,000 monolingual Circassian settlers in 1906. Until the 1940s, many merchants from As-Salti city and Nablus city came to Amman. It is worth mentioning that Nablus is an urban Palestinian city that uses [?], while As-Salti is the second major city after Amman, and its dialect is described as a sedentary Jordanian dialect uses the [g]. Between 1948-1986, Jordan's population increased from 500,00 to 2.3 million, and the number increased to more than three million by 2003 (Al-Wer, 2007). 
Investigating the changes described in Abdel-Jawad (1986), Al-Wer (2007) thoroughly described the formation of Amman's dialect since the beginning of the last century until now. Al-Wer used socio-linguistic interviews to collect her data for the ongoing research she called "Amman Project". The study shows Amman's dialect evolving through three generations: the first one (arrived as adults), the second one (arrived very young), and the third one (was born in Amman). They were the grandparents, parents, and grandchildren of two families from the two input backgrounds: As-Salti and Nablus.

Al- Wer research covers the changes in three aspects: socio-linguistics, morphology and phonology. The first generation developed two changes as Al-Wer's data show. Participants originally from As-Salti did not use [č $]$ which is one of the most noticeable features of the original dialect. Al-Wer justified this change by the fact that the dialect of the city was already undergoing some changes. In addition, female Jordanian speakers used few tokens with [?] and male Palestinian speakers used some tokens with [g]. The second generation showed "very chaotic variability" using [?] and [g] (Al-Wer, 2007).

The grandchildren's generation showed that the formation of the dialect was completed. Moving from chaos to order, the third generation showed a systematic "stylistic and social reallocation" since $[\mathrm{g}]$ and [?] both survived the process of leveling during the contact between dialects. Both variables got new social and linguistic functions in the newly formed dialect (Britain \& Trudgill, 2005).

The third-generation speech patterns, as Al-Wer (2007) findings show, were: [?] is used among Palestinian males (talking to each other), [g] is used among Jordanian males, [?] is used by both groups when talking to females, and [g] is used by both groups in mixed 
(Jordanian and Palestinian) males' groups. Lastly, females, regardless of their background use [?] consistently.

\section{The social context}

Historically, urban dialects were associated with modernization. Cities like Beirut, Jerusalem, Damascus, and Haifa with [?] speaking population were looked at as supralocal dialect (Al-Wer, 2007; Holes, 1995). During the Ottoman rule and until the late 19th century, those cities were considered cultural centers. They had universities, and already well modernized social and economic systems. Since Jordan witnessed a relatively late modernization process compared to other cities, many intellectual and political elite families moved to Amman after forming the new state, which became the home of Arab nationalist movements in general. As Al-Wer (2007) explained, female Jordanian speakers from the first generation who got the chance to contact urban speakers from Syria and Palestine adopted [?] as a way of adopting a more prestigious status This concept of "prestige and sophistication" was elaborated in many previous studies (Abd-El-Jawad, 1986; Holes, 1995). While [?] is associated with urban societies, [g] is associated with masculinity and a "pure Bedouin" identity; $[\mathrm{k}]$ and $[\breve{c}]$ which are typical rural features that seem to receive negative associations (Holes, 1995; Skarana, 2005).

In Amman's case, the socio-political situation played a major role in shaping those assumptions. Due to the lack of human resources, the first Jordanian governments were mainly Syrian and Palestinian. Later on, a new Jordanian movement demanded the "Jordanisation" of the system to reflect the Jordanian identity (Al-Wer, 2007). The As-Salti dialect was considered the pure reflection of the Jordanian identity. Here, $[\mathrm{g}]$ was associated with not only masculinity and Bedouin origins, but also with the dominant 
identity, which has the right to be in power positions. Overall, that situation explains the changes Al-Wer (2007) observed in the three generations she studied.

\section{Rural Palestinians in Amman}

Before 1940, Palestinians in Jordan were mainly urban intellectuals and political elites from urban Palestinian origins (Al-Wer, 2007). In contrast, the Palestinian immigrants between 1940s-1990s were farmers or had small jobs and industries (Holes, 1995).

In 1990, approximately 400,000 Palestinians sought refuge in Jordan after the war between Kuwait and Iraq, and they were all recognized as Jordanian citizens. As I heard from my father, who was born and lived in Kuwait for the first 18 years of his life, rural Palestinians [fallahi:n] (farmers) used to live close to each other in Kuwait and continue living near each other in Amman after the 1990 immigration. This observation is supported by the fact that the Palestinian society is sharply divided into city residents "Madanji:n" and townfolks “ fallahiin” (Al-Wer, 2007).

In addition, Holes (1995) describes the presence of Palestinians in Amman:

"Jordan. Although many of the immigrants became absorbed into the mainstream of Jordanian life, a considerable proportion, particularly of the less well educated and less well-off, clung on to their Palestinian identity, and tended to congregate in Palestinian communities, whether in refugee camps or particular suburbs of Amman” (p. 277)

Applying Al-Wer's (2007) three generations model on the rural Palestinian population (Kuwaiti immigrants), the first generations would be the grandparents who arrived to Kuwait as adults to work. The second generation would be the parents who were born and raised in Kuwait and arrived to Amman as adults. The third generation would be the 
grandchildren who were born and raised in Amman,-Given the interesting social and linguistic situation of the last group, this study will investigate its speech. It is also worth mentioning that no research has been done on this population before.

\section{This Study}

According to Al- Wer, females regardless of the origin use [?], while males show more variation males tend to use their hometown phoneme [?] or [g] with males from the same origin. In case of mixed group contexts, all males tend to use [g] (Al-Wer, 2007) Al Wer discusses this variation in terms of masculinity, femininity and identity. This study aims to investigate other aspects of this variation like age and social class.

Previous research conducted on Amman's dialect had limitations. The first gap is that the sample used in (Al-Wer, 2007) investigating the formation of Amman's dialect did not include rural Palestinians, although they are the majority of the Palestinian immigrants. The second gap was that studies like (Al-Wer \& Herin, 2011; Herin, 2013) do not include the $[\mathrm{q}]$ reflex $[\mathrm{k}]$ as variant, even when they drew a life cycle to [q] as phoneme, they did not consider how $[\mathrm{k}]$ was treated in Amman's speech community. The third gap is that (Abd-El-Jawad, 1986) was conducted before the Gulf war, when thousands of rural Palestinian immigrants sought refuge in Jordan in 1992 and later. Therefore, the fact that rural Palestinians lived in nearly closed communities and did not completely emerge into the hosting society must be a considerable variable.

Thus, the study research questions are:

1- Do the young rural Palestinians use [?] or [g] or [k]?

2- Is there a difference between males and females use of those sounds? 
3- How does Amman's community perceive the use of the different sounds regarding identity (origin), gender and social class?

4- Are there any other social associations (especially social class) acquiring importance on behalf of gender and origin?

Taking the previous research in account, and the fact that females use the glottal stop regardless of their origin and males use the three sounds in more variability, relation between gender, and identity, the following hypotheses were developed:

- Males tend to use $[\mathrm{g}]$ as convergence strategy with the host community also as a way to show masculinity. Females tend to use [?] since it is the prestigious linguistic variable also as a way to show femininity.

- The [?] and [g] sounds indicating social class association are getting more important by time.

\section{Methodology}

\section{Participants}

This study has two parts. The first one aims to investigates the use of [k, g, ?] in the young rural Palestinians who were born and raised in Amman. They are the first native generation in their community. Nine speakers from Amman participated in the production study. The average age was 19.4 and their ages ranged from 14- 27. Participants were divided into two groups based on gender. Age was also one of the demographical pieces of information collected. Table 2 below shows the age of participants. 


\begin{tabular}{ll}
\hline participants & age \\
\hline f1 & \\
\hline $\mathbf{f 2}$ & 16 \\
\hline $\mathbf{f 3}$ & 17 \\
\hline $\mathbf{f 4}$ & 18 \\
\hline $\mathbf{m 1}$ & 27 \\
\hline $\mathbf{m 2}$ & 16 \\
\hline $\mathbf{m 3}$ & 17 \\
\hline $\mathbf{m 4}$ & 17 \\
\hline $\mathbf{m 5}$ & 23 \\
\hline
\end{tabular}

Table 2: first procedure participants' age, "m" refers to male and "f" refers to female

As for the second part of the study, the population is expanded to include Amman's populations from different origins. 76 people from Amman participated the average age was 30.5 and their ages ranged from 15 to 73 . The second procedure aims to investigate whether the use of the phonemes is shifting from gender to social class.

\section{General info about the participants in procedure 2}

Seventy-six participants from Jordan took part in the perception task ${ }^{4}$. the dominant age is twenties which is ideal for investigatining the new dialect of Amman. Also, 57\% of participants went to colloge, which means they had at least 3 years of interaction with a wider range of population. $64 \%$ of the participants' were males, and $34 \%$ were females. $2 \%$ prefered not to say. Regarding the city of origins $56 \%$ of the participants said they come from Jordan and 36\% from Palestine. $41 \%$ of the participants live now in Amman.

\footnotetext{
${ }^{4}$ Responses from other nationalities were removed.
} 


\section{Figure 1: participants' age in procedure 2}

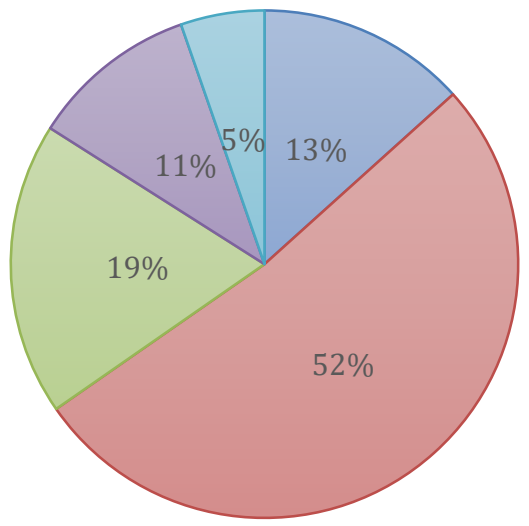

$\square$ ten - Twenty $\square$ Twenty - thirty $\square$ thirty - fourty $\square$ fourty - fifty $\square$ sixty and above

Comparing different age groups regarding the identification of the participant's own dialect, no major difference was found. Three participants from age group 20-30 left 3 comments about their dialect as "Ammani/ mix/ white" and those descriptions were not found in any other age group.

Procedures and Instruments

Data were collected through semi elicited naturalistic speech. This method was used in previous research (Abd-El-Jawad, 1986) and (Al-Wer, 2011,2007) in order to minimize a potential observer's effect and obtain more natural speech (Labov 1972), participants were asked to record themselves talking about their day in 2 different days each session lasted 3-5 minutes. ${ }^{5}$ This method helps participants to speak freely about their emotions and thoughts without addressing anyone. The semi structured interview happened after

\footnotetext{
${ }^{5}$ This method was used in accordance with the implications of Covid-19.
} 
collecting the data. Participants were asked several questions about their dialects, network, age, and their relation with the host community (see Appendix).

The second procedure was a questionnaire (See Appendix) distributed on Facebook pages and groups to reach out as many participants as possible. Participants should be living in Amman and be from Jordanian or Palestinian origins. The questionnaire has three sections. The first section is designed to collect demographical information to make sure that the participates meet the criteria the second section is designed to collect data about the linguistic background of the participants. It contains questions about languages and dialects participants speak, also some questions about their parents' dialects to get a sense of what dialect participants speak at home. The third section is about identity perception. Participants listened to six short clips produced by three women and three men each one exclusively using one of the phonemes They are saying the same sentence but in three different ways using the three studied phonemes [?] [g] and [k]. The recordings contained 4 tokens in 1 minute span. bargaining was chosen as a topic of the given sentence which is very common behavior in Jordan.

"The Recording transcription: the phoneme in [] changes in the six recordings

Bisraha ba[g]darish atsaraf min endi $w$ aatiik sier, ish min ha[g]i ans mish sahib mahal bet [g]dar tistanna sahib el maha khams da[g] y[g] we beikoon hoon.

Translation: Honestly, I can't act on my own responsibility and give you a price. It is not my right to do that since I'm not the owner, you can wait the owner 5 minutes and he will be here. "

\begin{tabular}{|l|l|l|}
\hline & Gender & Sound \\
\hline
\end{tabular}




\begin{tabular}{|l|l|l|}
\hline Audio 1 & M & {$[?]$} \\
\hline Audio 2 & M & {$[\mathrm{g}]$} \\
\hline Audio 3 & M & {$[\mathrm{k}]$} \\
\hline Audio 4 & F & {$[?]$} \\
\hline Audio 5 & F & {$[\mathrm{g}]$} \\
\hline Audio 6 & F & {$[\mathrm{k}]$} \\
\hline
\end{tabular}

Table 3: the audio

Another reason to choose this topic in particular is that Amman is geographically and socially divided into high class (western Amman) middle and low class (eastern/southern/central Amman). This distinction will help in assessing whether the sounds have formed an association with social class. After listening to each record, participants have questions about the dialect used, attitudes, assumptions about origins and social class (guessing the location of the shop).

\section{Analysis}

The first procedure targeted the first generation of Palestinian refugees from rural origins whom their families fled the gulf war in $1990 \mathrm{~s}^{6}$. The researcher classified the productions in order to determine the frequency of the phonemes for each participant. In addition, a rater who is familiar with Arabic phonemes and is a native speaker confirmed the classification and the frequency ratio. The number of tokens was calculated, then the percentages were calculated for each reflex and participant.

\footnotetext{
${ }^{6}$ Due to COVID-19 impact, only 9 participants provided data
} 
As for the second procedure, Google forms was used to distribute the questionnaire. For each audio, the responses were measured and converted to percentages. Some percentages did not sum up to $100 \%$ since some participants left the questions blank.

\section{Results}

First procedure: production data

The first two research questions aimed to investigate whether the population follows the same generalizations found in previous research. The first part of the hypothesis states that males will use $[\mathrm{g}]$ more in their speech. males' data, which shows a similar pattern to that in the hypothesis where males have [g] as their unmarked choice. Figure 2 below shows that all five males, regardless their age, use [g] more. None of them used [?]. Only participant (m3) used [k] slightly less than [g].

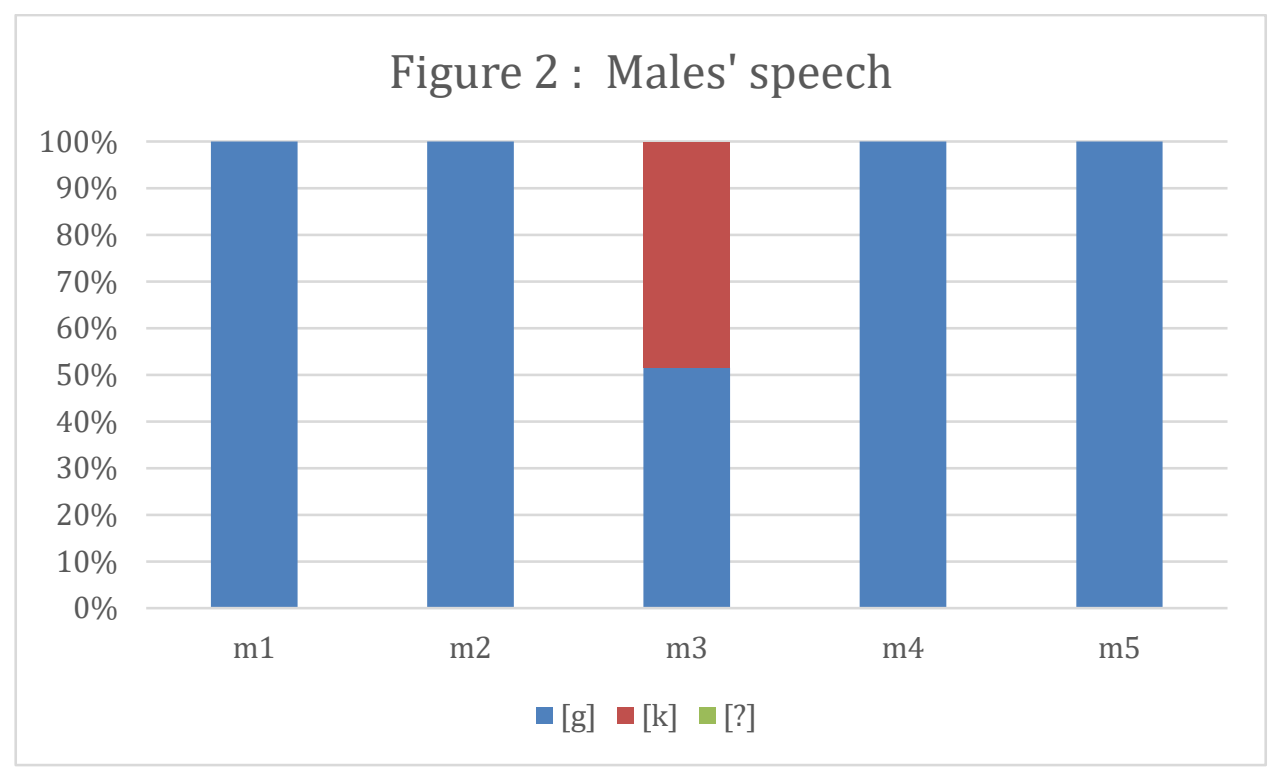


The females' data show more variation. Three of the participants used [?] more often. That agrees with the second hypothesis where females tend to use the glottal stop. Participants (f4) and (f1) are typical examples for this hypothesis; they used [?] as an unmarked choice. Participant (f3), on the other hand, used the variable [g] only, and did not use the glottal stop or [k]. And she explained in the semi structured interview that with the fact that all the members in her network are Jordanians. The last participant (f2), used the three variables, and [k] was used the most this can be due to her young age and to the fact that she is living and studying in a neighborhood with Palestinian majority.

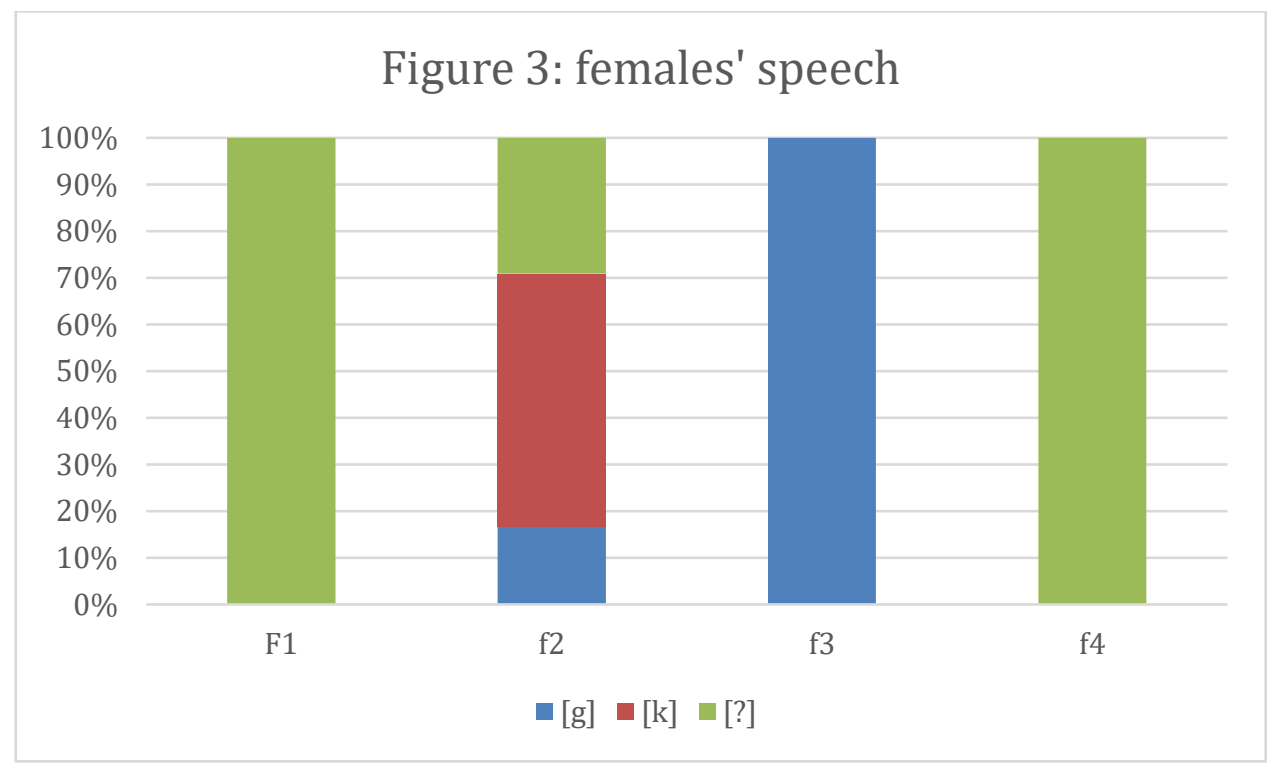

It seems that the two hypotheses work to some extent. Although males completely avoid using [?] participant (m3) still showed a variation between [k] and [g]. However, females' use of the variables fairly follow the second hypothesis; there is a tendency to use [?]. Yet, the variation, especially in the speech of participants (f2), (m1), (f3), will be discussed in the discussion section.

Second procedure: Perception task 
The third and fourth research question investigates how does-Amman's community perceives the use of the different sounds regarding identity (origin), gender and social class? and whether there are any other social associations (especially social class) acquiring importance on behalf of gender and origin.

The variation in the use of the three sounds led us to question the social associations of those sounds and what they truly assemble for Amman's society in the view of the social changes and the emergence of Amman's new dialect. Therefore, a questionnaire was designed to investigate the social context of this variation.

As discussed in the methodology section, the questionnaire aimed to investigate the social assumptions and association of the three reflexes.

\section{The recordings}

Six identical recordings, three for each gender were presented in the questionnaire. Those recordings were produced by volunteers living in Amman. Participants were asked to identify the dialect they heard, to answer questions about how they perceived the women (feminine, masculine, pleasant, not pleasant, educated or not educated). They also were asked to identify the location of the shop the woman/ man works in and the social class she belongs to.

\section{Identifying the dialect}

Table 4 below shows the responses for each gender. Participants identified the dialect they

listened to. Although the sound [?] does not exist in any Jordanian phonemic inventory $23 \%$ perceived it as Jordanian and $22 \%$ as Palestinian. That may be an evidence on the 
emergence of Amman's new dialect. It is worth mentioning that some participants did not answer the questions, so in many cases the percentages do nut sum up to $100 \%$.

\begin{tabular}{ccccc}
\hline \multicolumn{5}{c}{ Jordanian/ Palestinian } \\
\hline \multirow{2}{*}{ male } & {$[\mathrm{g}]$} & {$[\mathrm{k}]$} & {$[\mathrm{P}]$} \\
\hline \multirow{2}{*}{ female } & Jordanian & $42 \%$ & $6 \%$ & $24 \%$ \\
\cline { 2 - 5 } & Palestinian & $16 \%$ & $50 \%$ & $19 \%$ \\
\cline { 2 - 5 } & Jordanian & $36 \%$ & $42 \%$ & $23 \%$ \\
\cline { 2 - 4 } & Palestinian & $14 \%$ & $3 \%$ & $22 \%$ \\
\hline
\end{tabular}

Table 4: identifying the dialect of the speaker

Age groups were also considered as a variable during the process of analysis, yet no major difference was found. Age group 20-30 left comments about the males using [k] saying "never heard of a guy uses $k$ instead q" and "this can't be Jordan!"

\section{Education}

Table 5 shows the responses regarding the education. Males who use the glottal stop were assumed to be totally educated. It appears that [k] sound is often related with not educated people as well as low social status.

\begin{tabular}{ccrrr}
\hline \multicolumn{5}{c}{ Education } \\
& {$[\mathrm{g}]$} & {$[\mathrm{k}]$} & \multicolumn{1}{c}{$[\mathrm{P}]$} \\
\hline \multirow{2}{*}{ male } & educated & $18 \%$ & $8 \%$ & $27 \%$ \\
\cline { 2 - 5 } female & not educated & $4 \%$ & $16 \%$ & $0 \%$ \\
\cline { 2 - 5 } & educated & $13 \%$ & $5 \%$ & $20 \%$ \\
\cline { 2 - 5 } & not educated & $15 \%$ & $20 \%$ & $30 \%$ \\
\hline
\end{tabular}

Figure 5: education assumptions

\section{Social class}


Participants perceived males using the glottal stop to have higher social status by $36 \%$ while using $[\mathrm{k}]$ is associated with low status as discussed before. That assumption applies also on females although it is more common to females from mid class to use the glottal stop.

\begin{tabular}{|c|c|c|c|c|}
\hline & \multicolumn{4}{|c|}{ Social class } \\
\hline \multirow[t]{4}{*}{ male } & \multicolumn{2}{|c|}{ [g] } & \multicolumn{2}{|c|}{ [?] } \\
\hline & high & $3 \%$ & $1 \%$ & $36 \%$ \\
\hline & mid & $87 \%$ & $68 \%$ & $58 \%$ \\
\hline & low & $10 \%$ & $31 \%$ & $6 \%$ \\
\hline \multirow[t]{3}{*}{ female } & high & $1 \%$ & $3 \%$ & $19 \%$ \\
\hline & mid & $77 \%$ & $67 \%$ & $75 \%$ \\
\hline & low & $22 \%$ & $30 \%$ & $6 \%$ \\
\hline
\end{tabular}

Table 6: social class assumptions

Comparing age groups results, the age group $60+$ rated the sounds $[\mathrm{k}]$ and $[\mathrm{g}]$ to be $100 \%$ middle class and the glottal stop to be $76.3 \%$ to be middle class. The age groups between 10 to 50 years old showed more variability. For example, the age group 10-20 rated the female using [g] 55.5\% as high class and $44.4 \%$ as middle class. This can be due to the economic and demographic changes happened in the last decades in Jordan where the distinction between social classes became more visible.

\section{Masculinity and femininity}

As predicted in the hypothesis, the use of glottal stop was perceived as more feminine. Interestingly, males using glottal stop was so close $17 \%$ of the responses considered masculine. $18 \%$ considered it feminine which explain the shift towards the social class association. Females using [g] seems not to be associated to gender as much as males using the same sound. This observation will be discussed further in the next chapter. 


\begin{tabular}{|c|c|c|c|c|}
\hline \multicolumn{5}{|c|}{ Masculinity / Femininity } \\
\hline & & [g] & {$[\mathrm{k}]$} & [?] \\
\hline \multirow[t]{2}{*}{ male } & masculinity & $40 \%$ & 39 & $17 \%$ \\
\hline & femininity & $2 \%$ & $1 \%$ & $18 \%$ \\
\hline \multirow[t]{2}{*}{ female } & masculinity & $11 \%$ & $10 \%$ & $2 \%$ \\
\hline & femininity & $19 \%$ & $30 \%$ & $44 \%$ \\
\hline
\end{tabular}

Figure 7: assumptions about masculinity and femininity

\section{Pleasantness}

Responses in table 8 below shows that more people are perceiving males using glottal stop as pleasant. The $[\mathrm{k}]$ reflex seems to be the least pleasant sound and that can be justified by the fact that it's associated with Palestinian identity. [g] sound is assumed to be pleasant in both genders but slightly more in males' speech.

\begin{tabular}{ccrrr}
\hline \multicolumn{5}{c}{ Pleasantness } \\
& \multicolumn{1}{c}{$[\mathrm{g}]$} & \multicolumn{1}{c}{$[\mathrm{k}]$} & \multicolumn{1}{l}{$[\mathrm{P}]$} \\
\hline \multirow{3}{*}{ male } & pleasant & $31 \%$ & $24 \%$ & $25 \%$ \\
\cline { 2 - 5 } & unpleasant & $5 \%$ & $12 \%$ & $13 \%$ \\
\hline \multirow{2}{*}{ female } & pleasant & $19 \%$ & $27 \%$ & $29 \%$ \\
\cline { 2 - 5 } & unpleasant & $9 \%$ & $8 \%$ & $2 \%$ \\
\hline
\end{tabular}

\section{Figure 8: assumptions about pleasantness}

Age groups showed no difference rating gender or peasantness, yet participants from age group 10-20 left comments like “Very sweet”, "polite!” “I felt comfortable, I don't know why"

In the next chapter, the results will be discussed in more details regarding identity construction and gender, social class associations. 


\section{Discussion}

In order to get a better understanding of the first procedure results, a semi structured interview was conducted with the participants (See Appendix) where participants were asked several questions about their dialect, their family members' dialects, their perception of the three sounds, and finally their own identity. The questions were sent to the participants via email and they responded in small paragraphs.

In addition, the questionnaire (second procedure) contained long answer questions targeting the same aspects such as the need of changing the dialect.

\section{Femininity Vs Masculinity}

Previous studies have revealed the relationship between the three sounds [k], [?] and [g] and femininity and masculinity. Al -Wer (2007) explored the social reasons why Jordanian females use [?]. She found that the glottal stop is associated with femininity and modernization. Females and males from rural Palestinian origins share the same association.

Participant (m5), a 27-year-old working male expressed why he prefers females that use [?], "Girls using [?] are more feminine, I would choose a girl that speaks this way to marry her, I can 't tolerate a girl that speaks tougher than me!". Associating [?] with being feminine appeared in every participant's answer. "Girls use [?] to appear coquette" participant (f3) answered. On the other hand, males' use of this sound is stigmatized in some situations. In the semi structured interview, participants were asked to imagine the responses in this hypothetical situation: Imagine there is a fight, and one of the boys used [?], what will happen after ? Participant (m3) said: “they won't let him speak again; 
he is not a man!" while participant (m4) said: "no one will speak like that! Especially in a fight!". Females' responses share the same point of view; they refer to men using [?] as "soft".

Although there is a strong link between the glottal stop and femininity in males' speech, questionnaire results support this idea where participants perceived males using the glottal stop to have higher social status by $36 \%$ and $27 \%$ educated and $0 \%$ not educated. Therefore, participants were asked to guess the location of the shop mentioned in the recording. 100\% of the participants assumed that [?] recording location was west Amman or high-class malls. [g] sound was associated with middle to low class locations such as downtown area, north Jordan, center- south / east Amman. [k] sound was often located in Palestinian refugee camps and associated with lower class and lower education levels Another observation mentioned in participant (m4)'s answer about men using [?] in their speech, "the use of [madanii] (urban) dialect is not exclusively to act feminine, when I moved to a private, very expensive university, everyone speaks this way. In my old university in Al-zarqa City, they could beat you if you talk this way". Another similar comment was made by participant (m3), "racism in Jordan is not about being Palestinian or Jordanian anymore, it is about being very rich or poor". This adds another dimension to the use of the linguistic variable [?], making it not "exclusive" for showing femininity and masculinity, but as an indicator of social class and education.

\section{Identity}

Figure 4 shows that $61 \%$ of participants didn't feel the need of changing their dialect. $26 \%$ answered with yes and the reasons can be summed as follows: 1- to act feminine/ 
masculine, 2- to be taken seriously, 3 - to fit in, 4- to communicate. Answers like "I was bullied because of my feminine/ Palestinian dialect" or "to be a man" were left by participants. One participant mentioned that this change was exclusively made "To fit in more with the Ammani community or to be taken seriously". Other participant answered" I was born speaking rural [fallahi] Palestinian dialect, early interacting with Ammani society I had to use the urban [madanii] then Jordanian dialect as a teenager to avoid racism and bullying” This answer will pave the next discussion of the first procedure participants.

\section{Figure 4: Have ou ever felt the need to change your dialect?}

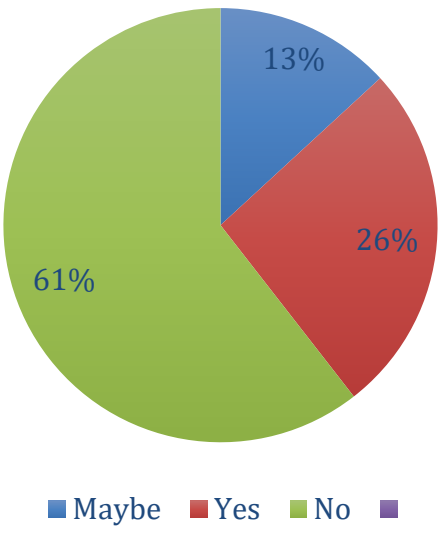

Although participant (m4) used the "Jordanian variable" [g] irrespectively, he still identified his dialect as [fallahi] rural Palestinian in the interview. The second participant (m2) admits that he never uses any [fallahi] dialect because he does not want to be different and said, "I don't want anyone to know my origins, it not because they can be racist, but I don't want them to make assumptions and treat me according to them. Do not think that racism based on origin is not real. I suffered a lot in school from that because I was a Palestinian. I was bullied a lot, that was 10 years ago where I was living in a Bedouin 
Jordanian neighborhood. I think it still happens but in specific areas in the capital”. The participant here is doing an aware convergence due to the insecure situation he experienced. The last male participant $(\mathrm{m} 2)$, did not show a full convergence, he stated that he does not have a problem in showing his Palestinian identity by quoting, "I don't feel that I need to change the way I talk, I don't think of every word I say".

For females, participant (f2) who is the twin sister of participant (m2), shared her brother's point of view, saying that she never felt the need to "pretend". Participant (f4) expressed that "everyone around use [?]". Although she did not use [k] at all, she still identified her dialect as [fallahi].

One of the questionnaire participants expressed the need of using $[\mathrm{g}]$ in her workplace as a civil engineer "I have to use it in field to be understood and taken seriously" she states.

The last female participant who showed more variation is (f3). She used [g] in her speech and never used other variables. The $[\mathrm{g}]$, as discussed before, is associated with masculinity and Jordanian identity. After gathering the data, I asked her about her friends' "network" and school. She says, "all my friends are Jordanians, in my class there are some Syrian girls but we don't like them and they don't like us". We can observe that network and the process of identity construction overlap with linguistic choices (Eckert, 1989, 2000). The participant is seeking a "Jordanian" identity against "Syrian". During the Syrian Crisis, hundreds of thousands of Syrians took refuge in Jordan. She describes the situation in her neighborhood by quoting, "my neighborhood was mostly Palestinians and Jordanians, now everyone is moving out and Syrians are replacing us". Feeling threatened, both Jordanians and Palestinians are considering themselves "us", one identity; against "them", the Syrian identity. 
Although it seems that only gender and identity and social class are influencing the use of [?], [g] and [k], a look through the data again may change this idea. Participants can be divided into two groups according to their age (17-18) and (23-27). For males, it is noticed that the youngest participant $(\mathrm{m} 1)=17$ still uses $[\mathrm{k}]$ often. He did not achieve a full convergence like the other participants who use [g] only. In females' participants, $(\mathrm{F} 2)=17$ also still use [k], unlike participant (f4) $=26$, who uses [?] only. Older participants are more likely to have more interaction with the society around them, considering that they went to college and worked.

\section{Conclusion}

Previous studies investigated the formation of Amman's dialect. The findings of Al- Wer, (2011) shows that males and females from Nabulsi and As-Salti origins use the [q] reflexes differently according to gender and origin. females regardless of their origin use the glottal stop and males' speech showed more variation where they used their origin's dialect with males from the same background and use $[\mathrm{g}]$ in any contexts interacting with mixed groups.

This study aimed to investigate whether young rural Palestinians who were born and raised in Amman as first generation are using the sounds [g], [?] and [k] the same way Jordanians and urban Palestinians use them in the previous research done by $\mathrm{Al}-\mathrm{Wer}$ (2007). This population has not been studied before. Complementing the previous research, more social constructs were added. This study conducted two procedures. The first one 
investigated the distribution of $[\mathrm{k}],[\mathrm{g}]$ and [?] reflexes. Data showed that participants are using $[\mathrm{k}]$ less as they get older. Males are using [g], not just to fit within the community, but also to show masculinity, and in some contexts, social class. It is predicted that with time, [?] in males' speech will be more accepted by the society because it is related to high social status despite being linked to femininity.

It was predicted that females will use [?] irrespectively, since it is associated with femininity and prestige. Data showed that females use it more the older they get. It was not predicted that females might actually use $[\mathrm{g}]$ to show solidarity against other identities also as an act of power in contexts like work place and public schools.

The second procedure results showed that Amman's community perceive males using [?] with high social status. This indicates that males use of the glottal stop is being accepted more since it's associated not only with gender but with social class.

Overall, this study still has some limitations. The number of participants was limited due to Covid -19 impact. The age variable needs more investigation since it is relatively new in this context. The new associations of the sounds also need more investigation on different ages/ origins and contexts. It is hard to conclude that youth from rural Palestinian origins are practicing convergence through host community pressures. The sound $[\mathrm{k}]$ is just the most "visible feature" of their dialect. Most of them believe that they speak at least a mix between the dialects. When they were asked to justify their answer, most of them said that the lexical choices are different.

This study predicts that in the future the reflexes $[\mathrm{g}]$ and [?] will not be associated to gender, instead they will be associated with social class especially after the recent economic 
developments in Jordan which was impacted severely by Covid- 19. It is also predicted that the presence of Syrian refuges will drive Palestinian refuges to identify themselves as Jordanians, thus start using the Jordanian dialect more. This can be justified by the fact Palestinians have been living in Jordan for more than 50 years now, and more than millions of them are already holding the Jordanian nationality.

Future studies can look into whether variables like age, interlocutor, and network can affect the distribution of the reflexes. Also, the presence of Syrian refugees may impact the identity perception of populations like Palestinian refugees. 


\section{References}

Abd-El-Jawad, H. R. (1986). The emergence of an urban dialect in the Jordanian urban centers. International Journal of the Sociology of Language, 61(1). https://doi.org/10.1515/ijs1.1986.61.53

Alfozan, A. (1989) Assimilation is classical Arabic [Unpublished doctoral dissertation]. Universit of Glasgow

Al Husseini, J. (2013). Jordan and the Palestinians. In Atlas of Jordan: History, territories and society (pp. 230-245). Beyrouth: Presses de l'Ifpo.

Al-nahar, M. (2013). The first traces of man. The Palaeolithic period ( $<1.5$ million $-\mathrm{ca}$ 20,000 years ago). In Atlas of Jordan: History, Territories and Society (pp. 94-99). Beyrouth: Presses de l'Ifpo.

Al-Wer, E. (2007). 'The formation of the dialect of Amman: From chaos to order. In Routledge Arabic Linguistics Series. Arabic in the City: Issues in Dialect Contact and Language Variation. (pp. 55-76). London: Routledge.

Al-Wer, E., \& Herin, B. (2011). The lifecycle of Qaf in Jordan. Langage et Société, 138(4), 59. https://doi.org/10.3917/1s.138.0059

Bakhit, A., Pascual, J.-P., \& Mundy, M. (2013). The early Ottoman era. In Atlas of Jordan: History, territories and society (pp. 188-197). Beyrouth: Presses de l'Ifpo.

Britain, D., \& Trudgill, P. (2005). New dialect formation and contact-induced reallocation: Three case studies from the English fens. International Journal of English Studies (IJES), 5. https://doi.org/10.6018/ijes.5.1.47951

Cantineau, J. (1938). Remarques sur les parlés de sédentaires syro-libano-palestiniens. Bulletin de La Société de Linguistique de Paris, 4, 80-89.

Cleveland, R. L. (1963). A Classification for the Arabic dialects of Jordan. Bulletin of the American Schools of Oriental Research, 171, 56-63. https://doi.org/10.2307/1355607

Eckert, P., (1989). Jocks and Burnouts: Social Categories and Identity in the High School. New York: Teachers Press. 
Eckert, P., (2000). Linguistic Variation as Social Practice: The Linguistic Construction of Identity in Belten High. Malden. MA: Blackwell.

Herin, B. (2013). Do Jordanians really speak like Palestinians? Journal of Arabic and Islamic Studies, 13, 99-114.

Holes, C. (1995). Community, dialect and urbanization in the Arabic-speaking Middle

East. Bulletin of the School of Oriental and African Studies, University of London, 58(2), 270-287.

Kerswill, P. (2018). 1. Dialect formation and dialect change in the Industrial Revolution: British vernacular English in the nineteenth century. In Southern English Varieties

Then and Now (pp. 8-38). https://doi.org/10.1515/9783110577549-002

Méouchy, N., Neveu, N., \& Ababsa, M. (2013). The Hashemites and the creation of Transjordan. In Atlas of Jordan: History, territories and society (pp. 212-221). Beyrouth: Presses de l'

Neveu, N. (2013). The Impact of Ottoman Reforms. In Atlas of Jordan: History, Territories and Society (pp. 198-201). Beyrouth: Presses de l'Ifpo.

Labov, W. (1972) Sociolinguistics patterns. Philadelphia: University of Pennsylvania Press.

Palva, H. (2015). A General classification for the Arabic dialects spoken in Palestine and Transjordan. Studia Orientalia Electronica, 55(1984), 357-376.

Skarana, A. K. (2005). The linguistic status of the modern Jordanian dialects. Arabica, $52(4), 522-543$.

Smith, I., \& Trudgill, P. (1987). Dialects in Contact. Language, 63, 675 . https://doi.org/10.2307/415025

Van Hear, N. (1995). He Impact of the involuntary mass "Return" to Jordan in the wake of the Gulf Crisis. The International Migration Review, 2, 352-374.

Williams, A., \& Kerswill, P. (1991). Dialect levelling Countinuaty VS. Change in Milton Kyenes, Reaing and Hull. In Urban voices. Accent studies in the British Isles (pp. 141-162). London: Arnold. 


\section{Appendix}

MSA phonetic inventory

\begin{tabular}{|l|l|}
\hline$[?]$ & Voiceless glottal stop \\
\hline$[\mathrm{b}]$ & Voiced bilabial stop \\
\hline$[\mathrm{t}]$ & Voiceless alveolar stop \\
\hline$[\mathrm{d}]$ & Voiced alveolar stop \\
\hline$[\mathrm{k}]$ & Voiceless velar stop \\
\hline$[\mathrm{q}]$ & Voiced uvular stop \\
\hline$[\mathrm{d}]$ & Voiced interdental fricative \\
\hline$[\mathrm{h}]$ & Voiceless glottal fricative \\
\hline$[\mathrm{s}]$ & Voiceless alveo - palatal fricative \\
\hline$[\mathrm{z}]$ & Voiced alveo- palatal fricative \\
\hline$[\mathrm{n}]$ & Voiced alveolar nasal \\
\hline$[\mathrm{m}]$ & Voiced bilabial nasal \\
\hline$[\theta]$ & Voiceless interdental fricative \\
\hline$[\mathrm{r}]$ & Voiced alveolar trill \\
\hline$[\mathrm{l}]$ & Voiced alveolar lateral \\
\hline$[\mathrm{y}]$ & Voiced Alvoe-paltal (semi vowel) \\
\hline$[\mathrm{w}]$ & Voiced bilabial (semi vowel) \\
\hline$[\mathrm{f}]$ & \\
\hline$[\mathrm{h}]$ & Voiceless labiodental fricative \\
\hline$[\mathrm{x}]$ & \\
\hline & \\
\hline
\end{tabular}




\begin{tabular}{|l|l|}
\hline$[\mathrm{\gamma}]$ & Voiced uvular fricative \\
\hline$[\tilde{]}]$ & Voiceless alveo-palatal fricative \\
\hline$[\underline{\mathrm{t}}]$ & Voiced emphatic alveolar stop \\
\hline$[\underline{\mathrm{d}}]$ & Voiced emphatic alveolar fricative \\
\hline$[\underline{\mathrm{s}}]$ & Voiceless emphatic alveolar fricative \\
\hline$[\underline{\jmath}]$ & Voiced emphatic interdental fricative \\
\hline$[\mathrm{C}]$ & Voiced pharyngeal fricative \\
\hline Long vowels: [a: , u:, i: ] Short vowels [a, u, i]
\end{tabular}

The semi structure interview in procedure 1 :

Q1: What is the most distinguishable feature (sound/ register) of your dialect?

Q2: How do describe your dialect (Urban, Bedouin, rural, other)? 
Q3: Did you feel any pressure in school/social life to change your dialect?

Q4: Why do you think girls tend to say "Pal" instead of "gal" or "kal"?

Q5: Why do you think boys tend to say "gal"? If a boy used "Pal" would that be weird?

Q6: if some heard you speaking, would they know from where you are?

Q7: imagine a boy using [?] in a fight, what are the responses would be?

Questionnaire (English version)

Subject Number

\section{Demographical info}

- What is your age?

Sex: $M_{ـ}$

- What is your city of origin?

- Where do you live now?

- Where were your parents born?

- Have you lived in Other (specify) places before? Yes/ No

- If yes please specify where and for how long

- What is your highest educational degree earned?

\section{Linguistic background}

- What languages do you speak?

- What languages do/did your parents speak?

- What dialects do/did your parents speak?

- How would you describe your dialect?

- Rural 
- Urban

- Bedouin

- Jordanian,

- Palestinian

- Other (specify)

- Have you ever felt the need to change your dialect for any reason? Yes/ No If yes please tell us why......

- do you think people can identify where you are form based on the way you talk? Yes/no, why? / what is their assumption?

\section{Identity perception}

Now you will listen to 6 very short clips for a person in shop, please answer the questions after each clip.

\section{Clip 1}

- What dialect does the lady have?

- Rural

- Urban

- Bedouin

- Jordanian,

- Palestinian

- Other (specify)

- What social class do you think she belongs to?

- High

- Medium

- low

- Where is the shop located?

- How would you describe her attitude? Choose as many as you want 
- Feminine

- Masculine

- Educated

- not educated

- Pleasant

- Not pleasant

- Would you like to add any additional comments about the way this person talks?

\section{Clip 2}

- What dialect does the lady have?

- Rural

- Urban

- Bedouin

- Jordanian,

- Palestinian

- Other (specify)

- What social class do you think she belongs to?

- High

- Medium

- low

- Where is the shop located?

- How would you describe her attitude? Choose as many as you want

- Feminine

- Masculine

- Educated

- not educated

- Pleasant

- Not pleasant

- Would you like to add any additional comments about the way this person talks? Clip 3

- What dialect does the lady have?

- Rural 
- Urban

- Bedouin

- Jordanian,

- Palestinian

- Other (specify)

- What social class do you think she belongs to?

- High

- Medium

- low

- Where is the shop located?

- How would you describe her attitude? Choose as many as you want

- Feminine

- Masculine

- Educated

- not educated

- Pleasant

- Not pleasant

- Would you like to add any additional comments about the way this person talks?

Clip 4

- What dialect does the man have?

- Rural

- Urban

- Bedouin

- Jordanian,

- Palestinian

- Other (specify)

- What social class do you think he belongs to? 
- High

- Medium

- low

- Where is the shop located?

- How would you describe his attitude? Choose as many as you want

- Feminine

- Masculine

- Educated

- not educated

- Pleasant

- Not pleasant

- Would you like to add any additional comments about the way this person talks?

\section{Clip 5}

- What dialect does the man have?

- Rural

- Urban

- Bedouin

- Jordanian,

- Palestinian

- Other (specify)

- What social class do you think he belongs to?

- High

- Medium

- low

- Where is the shop located?

- How would you describe his attitude? Choose as many as you want

- Feminine

- Masculine

- Educated

- not educated

- Pleasant 
- Not pleasant

- Would you like to add any additional comments about the way this person talks? Clip 6

- What dialect does the man have?

- Rural

- Urban

- Bedouin

- Jordanian,

- Palestinian

- Other (specify)

- What social class do you think he belongs to?

- High

- Medium

- low

- Where is the shop located?

- How would you describe his attitude? Choose as many as you want

- Feminine

- Masculine

- Educated

- not educated

- Pleasant

- Not pleasant

- Would you like to add any additional comments about the way this person talks? 